\title{
Medicare woes prompt AMA brouhaha
}

$\mathrm{S}$ age and veteran delegates to the American Medical Association (AMA) annual meeting say the vast majority of resolutions have historically been "always about money."

But with the American health care system in upheaval and the nation's doctors under what AMA Past-President Dr. Peter Carmel dubbed a "cloud of anxiety," those experienced vets say there's been a subtle change in recent years. "It's now always about health reform and money."

No better evidence of that proposition was found than in deliberations over a proposal to have the AMA endorse and campaign for the introduction of "premium-based" Medicare for America's senior citizens.

The AMA Council on Medical Service and an AMA reference committee (one of eight groups that essentially vet all resolutions before they hit the floor and give a thumbs-up or thumbs-down to proposals) had approved the proposition for ratification by the 2012 AMA House of Delegates Annual Meeting in Chicago, Illinois. But scant days before the vote on the issue was scheduled to take place, AMA brass yanked it from the agenda, saying "there is a need to put in additional work on a revised report that addresses a number of complicated policy issues."

Former AMA president Dr. Donald Palmisano promptly penned a missive on his website calling the move "shocking" (http://intrepidresources.com/djp _update/?p=851). "Are we to have the world think AMA does not focus on what is best for the patient-physician relationship but instead genuflects to politicians. Time to get off bended knee. Time to cut the chains that bind physicians with price-fixing and coercion. We are Americans, not serfs. A sad day," he wrote.

The irate Louisiana delegation scrambled to craft a "late" resolution calling on the AMA to "support transitioning Medicare to a premium support program." As such, it would have needed a

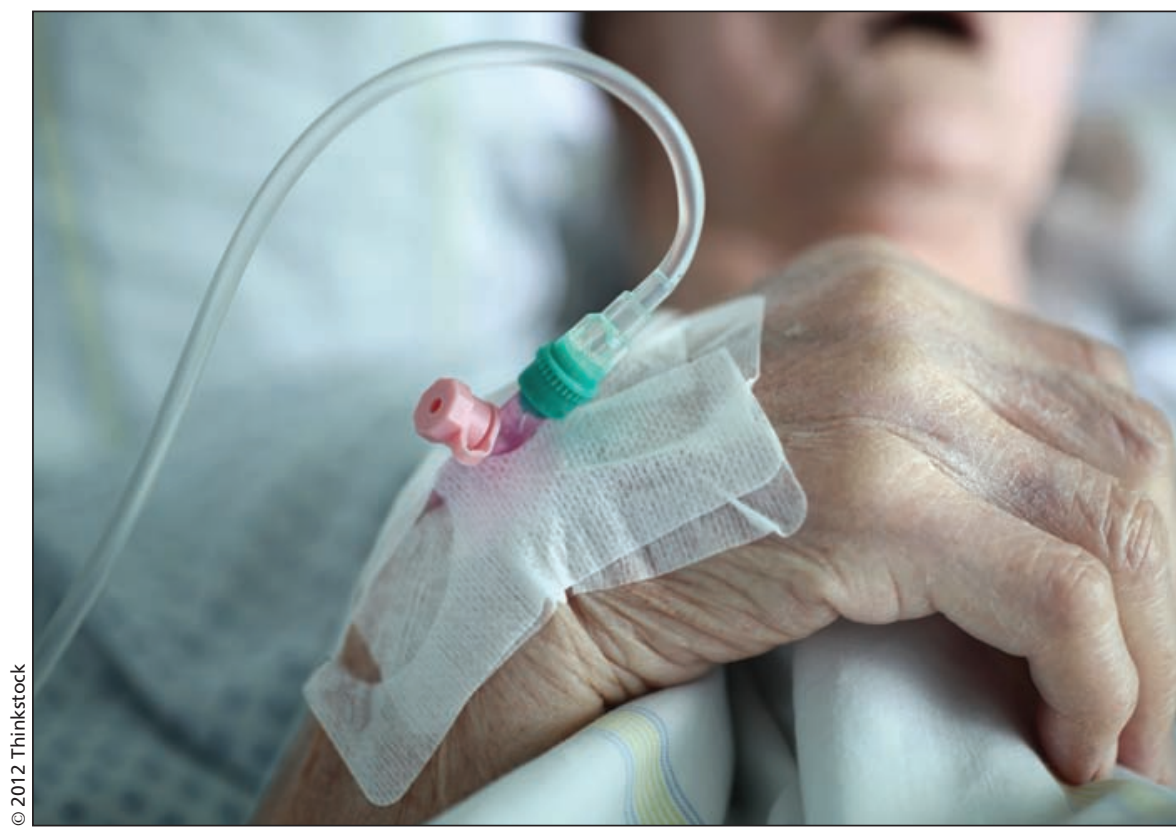

As envisioned, premium-based Medicare would involve giving money (with the amount possibly means-tested) to senior citizens in the form of vouchers, which they could use to purchase health insurance, rather than having the federal government absorb the cost of their health care. Critics fear it might lead to substantial variations in the level of care that senior citizens receive.

two-thirds majority (rather than standard $50 \%$ ) to become AMA policy.

The fireworks hit the proverbial fan as delegates lined-up to voice their opinions.

As envisioned, premium-based Medicare would involve giving money (with the amount possibly meanstested) to senior citizens in the form of vouchers, which they could use to purchase health insurance, rather than having the federal government absorb the cost of their health care. A highly charged political issue, such an approach is seen by some as a way to save the Medicare program, which is believed to be on the fast track to insolvency.

Several delegates lauded the approach as a means of achieving cherished American "choice" in terms of the delivery model they prefer for their health care and nothing less than cowardice in the face of Medicare's woes. "These may not be politically correct policies but they are medically correct policies," argued an Alabama delegate.
Others lambasted it as abandonment of seniors to the vagaries of the profitdriven health insurance industry, which would "cherry pick" the healthiest seniors and leave the elderly poor to their own devices. Urging changes to an "iconic" program like Medicare that might make it harder for some seniors to obtain care might also erode respect for the profession, argued another delegate.

Council on Medical Service Chairman Dr. Thomas Sullivan urged AMA to delay a decision and further refinement of options, telling delegates that the council was "worried how people will spin this out of control."

Eventually, the Louisiana resolution was revised to that effect to read that the AMA should "refine its policy regarding Medicare financing options, including a defined contribution program that would allow beneficiaries to purchase traditional Medicare or a private health insurance plan through a market place of competing health plans approved by the U.S. Department of Health and 
Human Services or its designee. Our AMA should consider mechanisms to adjust contributions in order to ensure that health insurance coverage remains affordable for all beneficiaries" and report back to the AMA's interim meeting in November.

Delegates overwhelmingly voted to do just that.

But America cannot wait too long before moving with funding reform of Medicare, argues Dr. Frederick White, the resolution's author and a cardiologist in Shreveport, Louisiana. "We feel that the American health care system and its funding is really reaching a point of impending financial distress. The time is running short."

In other resolutions, the notion of providing "choice" to Medicaid (which covers health care for the poor) patients prevailed as delegates approved the principle of giving "states the option to transition nonelderly and nondisabled Medicaid beneficiaries to a system of tax credits for the purchase of coverage."

Delegates also approved motions urging that women over the age of 40 be entitled to screening mammography if their doctors agree to it and that schools revise curriculum to include annual instruction on the causes, conse- quences and prevention of obesity. But the gathering rejected a motion that would have advocated allowing surrogate decision-makers to consent to living organ donation from patients in a persistent vegetative state. It also turfed an Arizona resolution that would have compelled AMA and its various boards and committees to end decades of "structured confidentiality" and make the minutes of all their deliberations available to the general membership (www.cmaj.ca/lookup/doi/10.1503/cmaj .109-4234). — Wayne Kondro, CMAJ

CMAJ 2012. DOI:10.1503/cmaj.109-4237 